\title{
Intensification of the process of decomposition of oil-water emulsions stabilized with hydrochloric acid
}

\author{
A.A. Kondratyuk, I.N. Karpenko, and V.V. Konovalov \\ Development and Exploitation of Oil and Gas Fields, Samara State Technical University, Samara, \\ Russia
}

\begin{abstract}
The major goal of oil and gas companies working in the oilfields on the late stages of development is to maintain a high level of hydrocarbon production. Analysis of well intervention techniques (WITs) in the oilfields of the Samara Region shows that most often the bottomhole area is treated with reagents containing hydrochloric acid, which significantly effects the efficiency of well fluid preparation processes. The paper summarizes the results of studies of the impact of hydrochloric acid on the rheological and near-surface properties of water-in-oil emulsions (WOEs). It is shown that the presence of acid and/or products of its reaction with the oil increases the stability of the water-in-oil emulsion. To enhance the process of decomposition of the water-in-oil emulsion stabilized with hydrochloric acid, a reagent was developed based on the non-ionic surfactants, alkaline agent and solvent, providing a significant reduction of the viscosity of water-in-oil emulsions and improving the efficiency of their decomposition.
\end{abstract}

\section{Introduction}

The major task of oil and gas industry companies working at oilfields in the late stages of development is to maintain a high level of hydrocarbon production. For this purpose, various well intervention techniques are used (WITs). Well interventions may affect the efficiency of processes of preparing the production fluid, especially when using chemical reagents of different types: polymers, surfactants, acids, alkaline agents, and so on; once in the production fluid, they affect the stability of oil-water emulsions and efficiency of oil preparation processes [1,2].

At present, many well intervention technologies are currently used in the oilfields of the Samara Region, including: putting new wells into operation from drilling, putting other new wells into operation, reconstruction of wells, formation fracturing, transitions, and commingling, off-stream well reactivation, bottom-hole treatment, accident elimination, repair, and insulation works, planned preventive maintenance, and others. The most frequently are the WITs involving treatment of the bottom-hole area (over $78 \%$ relating.), of which about $74 \%$ relatively use hydrochloric acid $(\mathrm{HCl})$, mostly in production $(55.5 \%$ rel.) and in injection wells (17.2\% rel.). The following types of bottomhole treatments are used: hydrochloric treatment (HCT) $-45 \%$ rel., treatment with acid-cut clay mud (ACC) - 
$12 \%$ rel., combined HCT using solvents - 7\% rel., combined ACC using solvents $-7 \%$ rel., large-volume bottom-hole treatment with self-diverting acid $-2 \%$ rel., acidic emulsions $1.7 \%$ rel., large-volume bottom-hole treatment (BHT) with gel acid $-1.5 \%$ rel., and others. Thus, of the wide range of existing BHT methods, in the oilfields of the Samara Region, acid $(\mathrm{HCl})$ treatment is mainly used.

As a rule, when performing the $\mathrm{BHT}$, to minimize the effects of $\mathrm{HCl}$ on the wellbore fluid collection and treatment system, wells typically return to operation after reaching a certain acidic value, but the process of reaching the required $\mathrm{pH}$ values of the produced fluid may be quite lengthy [2,3]. Even though the $\mathrm{pH}$ level of the produced fluid is monitored, some part of the $\mathrm{HCl}$ residue and/or products of its reaction may get into the oil collection system, which will affect the efficiency of preparation of the production fluid [1]. As a chemically active substance, $\mathrm{HCl}$ is capable of reacting with the water and the oil phases of the water-in-oil emulsion (WOE); as a rule, its stability increases, therefore, there is a need to change the dose of the demulsifier and/or adjust the process parameters of oil preparation facilities equipment.

The stability of the emulsion depends on a number of factors including the amount of hydrogen sulfide, asphaltenes, tar, and naphthenic acids in the oil phase, boundary tension at the interphase, oil gravity and viscosity, formation of the 'inhibiting' film (emulsion aging), etc. [4,5].

During well interventions involving $\mathrm{HCl}$ and when the latter interacts with the formation oil, there may occur asphaltene precipitation in a separate phase with some precipitation of sediments [6,7], which influences the efficiency of oil production and preparation processes.

The asphaltenes have a negative charge and are present in the oil as colloidal particles stabilized by tars [8]. Asphaltenes are finished emulsifiers $[9,10]$, whereas the tars do not have prominent emulsifying properties [11]. The tar sorption on the asphaltenes results in the formation of micellar structures, decreasing the stability of the emulsion [12-15]. The acid treatment destroys the micellar structures due to protonation [16], there appears the possibility for the asphaltenes to form heavier aggregates with their subsequent precipitation [17].

The acid is instrumental in changing the surface properties of oil emulsions by affecting the value of surface tension, dispersion ability of the system, and its rheology [18].

To evaluate the impact of $\mathrm{HCl}$ on the efficiency of oil dewatering processes, an analysis of changes in the water cut of oil was conducted on the preliminary water discharge units (PWDU), which showed a correlation between acid treatment and surges in the water-cut of oil leaving the water discharge units. A typical example is shown in Fig. 1, data on changes in the magnitude of water-cut oil coming out of the water discharge unit after BHT, involving the acid wave treatment and large-volume hydrochloric treat-ment on production wells. 


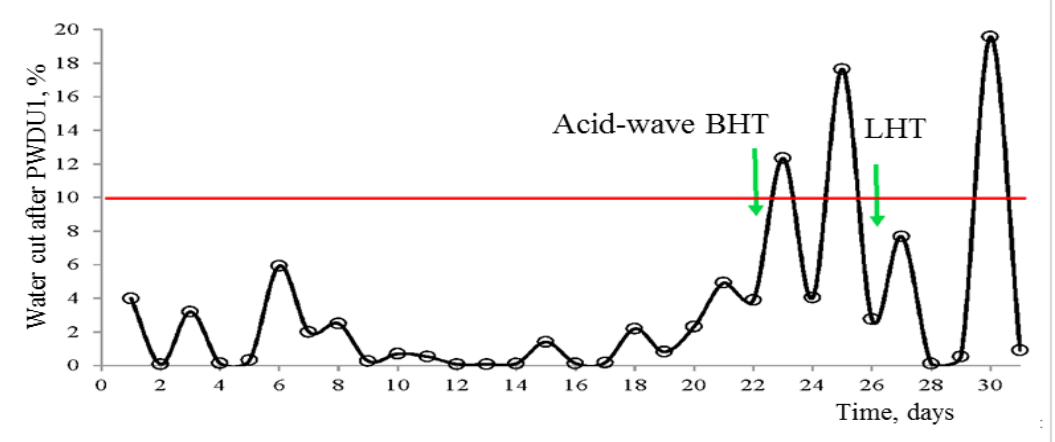

Fig. 1. Change in the water cut of oil leaving PWDU No.1 after the BHT with an acid wave and large volume HCT.

The analysis of changes in the water-cut of well fluid on the oil preparation facilities shows that treatment with $\mathrm{HCl}$ has an adverse effect on the efficiency of oil dewatering processes. It results in the increased operating costs of the transportation and preparation of oil, increased rate of corrosion of equipment, and possible process failures.

To mitigate the negative impact of hydrochloric acid on the efficiency of decomposition of water-in-oil emulsion, optimal conditions for the operation of oil preparation facilities should be provided, including adjustment of process parameters of equipment and dosage of de-emulsifiers; however, experiments have shown that even optimum dosages of deemulsifiers have not resulted in reaching the required degree of dewatering of the oil and water emulsion [19]. Another possible way of efficient destruction of stable water-in-oil emulsions is the use of additional reagents ensuring increased efficiency of de-emulsifier performance and dewatering of oil.

The task of this paper is to evaluate the impact of $\mathrm{HCl}$ on the surface and rheological parameters of oil and water emulsion and to find the reagent to intensify the process of their decomposition.

\section{Main points}

\subsection{The Method}

The experiments used oil with the following properties: gravity: $886 \mathrm{~kg} / \mathrm{m} 3$, dynamic viscosity: $17.88 \mathrm{mPa} \cdot \mathrm{s}$, asphaltenes content $\mathrm{w} / \mathrm{w}: 3.63 \%$, silica-gel tar content w/w: $5.7 \%$. To create the emulsion, formation water was used (gravity: $1182 \mathrm{~kg} / \mathrm{m} 3$, salinity: $247 \mathrm{~g} / \mathrm{l}$ ).

Rheological properties of the obtained emulsions were determined with the MCR 52 Anton Paar rheometer using the PP20 'plate-plate' measurement system with in the temperature range of $20^{\circ} \mathrm{C}$ and shear rate of $1 \ldots 100 \mathrm{~s}-1$.

The inter-phase tension (IPT) was measured using the spinning drop method on the SVT15N video tensiometer (DataPhysics). Each 6.0-6.4 $\mu$ l drop was introduced by a chromatographic syringe, and the IPT of each sample was registered once the system reached equilibrium.

The efficiency of decomposition of water-in-oil emulsions was tested by the generally accepted "Bottle Test" method by which the dewatering speed and residual content of water in the settled oil were measured. 


\subsection{Effect of Hydrochloric Acid on the Surface Parameters of Water-Oil Emulsion}

The measurement changes in the inter-phase tension shown in Fig. 2 demonstrate that the increased dosage of de-emulsifier results in lowered IPT, the character of obtained dependencies with various contents of the demulsifier and $\mathrm{HCl}$ being symbasic: initially, the inter-phase tensions are lowered and minimal values are reached, but with the $\mathrm{HCl}$ concentration above $1300-1400 \mathrm{ppm}$, a further increase in the IPT is observed. The observed patterns appear best without the presence of any demulsifier: as the dose of the IPT demulsifier increases, the increase is shown to be less.

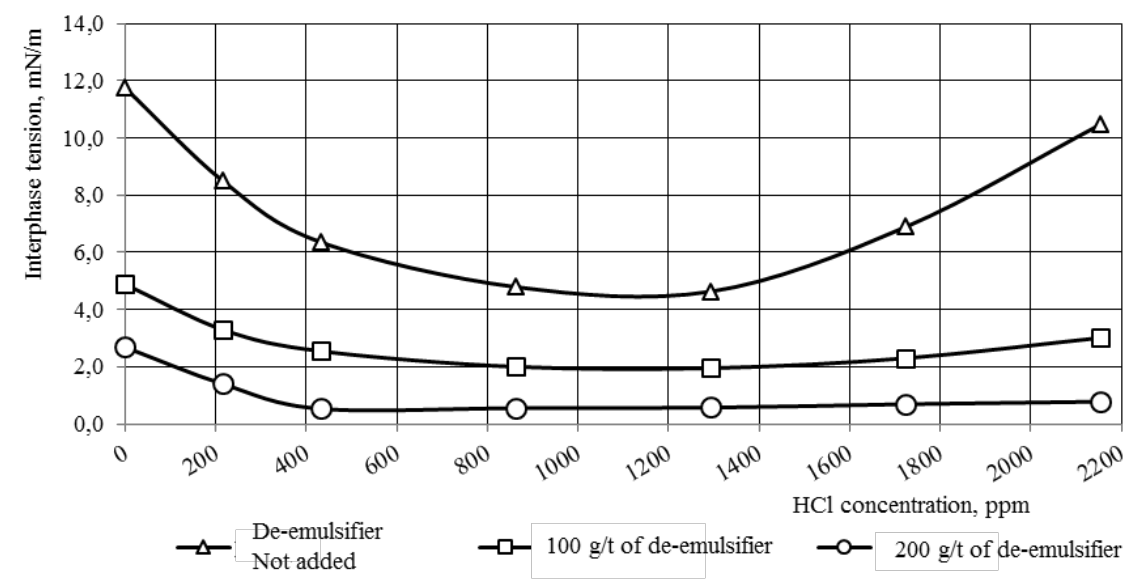

Fig. 2. Isotherm lines of inter-phase tension on the boundaries of 'oil-formation water-HCl' phases.

Studies of the IPT on the boundaries of the 'oil - formation water - $\mathrm{HCl}$ ' phases have shown that the increased content of demulsifier and $\mathrm{HCl}$ in the water-in-oil emulsion causes the reduction of the IPT level, yet the concentration of $\mathrm{HCl}$ of 1300-1400 ppm shows a further growth of the IPT. The observed patterns may be related to the process of protonation of tar and asphaltenes of oil [20,21], and the creation of an additional surface of phase interface, which increases the IPT value; this effect is most significant with low doses of demulsifier at $\mathrm{HCl}$ concentration in the water-in-oil emulsion above $0.1 \% \mathrm{w} / \mathrm{w}$.

To confirm possible sedimentation resulting from $\mathrm{HCl}$ and oil reaction, additional study was performed using the following method: at the first stage, a solution of oil and toluene was prepared to determine the amount of natural impurities in the oil; at the second stage, a solution of oil and hexane was prepared since the saturated hydrocarbons aid in settling down tars and asphaltenes; at the third stage, a solution of oil, hexane and hydrochloric acid was prepared. The results of the experiments (Fig. 3) showed that $\mathrm{HCl}$ stimulates the accumulation of sediments, especially at concentrations above $0.1 \% \mathrm{w} / \mathrm{w}$, which corresponds to the values obtained earlier in the studies of the IPT. 


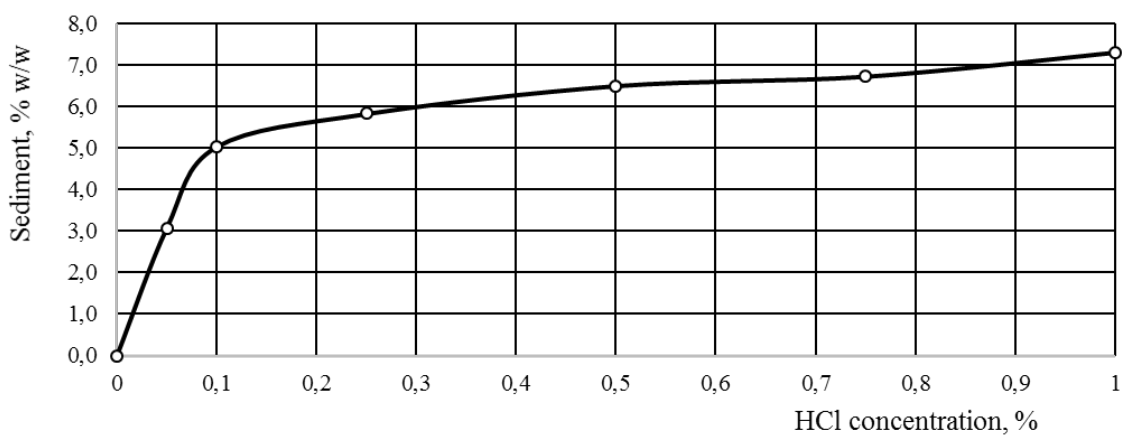

Fig. 3. Sediment accumulation following reaction of $\mathrm{HCl}$ and oil components.

\subsection{Effect of Hydrochloric Acid on the Rheological Properties of Water-in- Oil Emulsion}

To evaluate the $\mathrm{HCl}$ effect on the rheological properties of the water-in-oil emulsion, artificial emulsions were prepared with an acid content of $500 \mathrm{ppm}$. Once the acid was added to the water-in-oil emulsion, the acidic emulsion was mixed at $1000 \mathrm{rpm}$ and cured for one hour (aged). The rheological properties of water-in-oil emulsion with and without the addition of acid are shown in Table 1.

Table 1. Changes in the water-in-oil emulsion viscosity by the shear rate at $20^{\circ} \mathrm{C}$.

\begin{tabular}{cccccc}
\hline & \multicolumn{2}{c}{ Oil-in-water emulsion } & $\begin{array}{c}\text { Oil-inwater emulsion with } \mathrm{HCl} \\
(500 \mathrm{ppm})\end{array}$ & \\
\cline { 2 - 5 } Shear rate, $\mathrm{s}^{-1}$ & $\begin{array}{c}\text { Viscosity, } \\
\mathrm{mPa} \times \mathrm{s}\end{array}$ & $\begin{array}{c}\text { Shearing } \\
\text { stress, } \mathrm{Pa}\end{array}$ & $\begin{array}{c}\text { Viscosity, } \\
\mathrm{mPa} \times \mathrm{s}\end{array}$ & $\begin{array}{c}\text { Shearing } \\
\text { stress, } \mathrm{Pa}\end{array}$ & $\begin{array}{c}\text { Viscosity } \\
\text { change }\end{array}$ \\
\hline 5 & 1692 & 8 & 15489 & 77 & 9.15 \\
10 & 1026 & 10 & 7995 & 80 & 7.79 \\
30 & 714 & 21 & 3414 & 102 & 4.78 \\
50 & 700 & 35 & 2683 & 134 & 3.83 \\
70 & 736 & 52 & 2322 & 163 & 3.15 \\
100 & 781 & 77 & 2017 & 202 & 2.58 \\
\hline
\end{tabular}

Experiments showed that the addition of $\mathrm{HCl}$ to water-in-oil emulsions at a concentration of $500 \mathrm{ppm}$ significantly changes the rheological behavior of the emulsion. At the shear rate of $5 \mathrm{~s}^{-1}$, the oil-in-water and acid emulsion is over nine times higher than the dynamic viscosity of emulsion with no acid added. As the shear rate increases, the ratio of viscosities goes down but remains relatively high (dynamic viscosity of oil-in-water and acid emulsion at $100 \mathrm{~s}^{-1}$ is 2.5 higher than the viscosity of water-in-oil emulsion without acid). The analysis of data for the changes in the shearing stress from shear rate shows that the system with $\mathrm{HCl}$ added begins to demonstrate non-Newtonian properties.

Thus, the addition of acid results in changes of not only surface properties but rheological properties as well. For the selected test samples, the $\mathrm{HCl}$ effect resulted in an exponential increase in the viscosity of water-in-oil emulsion in the considered range of shear rates, which significantly increases the stability of emulsion [22,23].

The next stage of study involved assessment of the possibilities of decomposing the water-in-oil emulsion with the use of industrial demulsifiers. 


\subsection{Evaluation of Performance of Industrial Demulsifiers to Decompose Water-in-Oil Emulsions with $\mathrm{HCl}$ Added}

In order to decompose the water-in-oil emulsions stabilized with $\mathrm{HCl}$, a study was performed on the efficiency of water-in-oil emulsion decomposition using the widely accepted "Bottle Test" method, by which the rate of dewatering and residual water content in the settled oil were determined.

The experiment included the addition of $500 \mathrm{ppm}$ of $\mathrm{HCl}$ to the water-in-oil emulsion and mixing it for 1 hour, following which the emulsion was cured for one more hour (aging of water-in-oil emulsion). It is at a concentration of $500 \mathrm{ppm}$ that $\mathrm{HCl}$ starts to have a substantial impact on the dewatering process. Next, emulsion decomposition was tested using five industrial demulsifiers from various manufacturers currently used at the oil preparation facilities, with dosages ranging from 100 to $500 \mathrm{~g} / \mathrm{t}$.

The results of the study showed that industrial demulsifiers used at the oil preparation facilities did not provide complete separation of emulsion water, the best specimen provides 24\% dewatering (dosage: $500 \mathrm{~g} / \mathrm{t}$, settling time: 2 hours). An increase of settling time of the water-in-oil emulsion to 16 hours did not sufficiently improve the efficiency of the dewatering process. Increasing the temperature to $60^{\circ} \mathrm{C}$ improved the dewatering process, yet the final dewatering value is still quite low at $38 \%$.

A parallel experiment on the decomposition of water-in-oil emulsion free from $\mathrm{HCl}$ showed almost complete dewatering $(96 \%)$ of the emulsion in just one hour of settling.

Thus, $\mathrm{HCl}$ contributes to the production of stable water-in-oil emulsions decomposition, the decomposition of which by means of industrial demulsifiers is practically impossible. One of the main reasons for the underperformance of demulsifiers is a significant increase in the viscosity of water-in-oil emulsions with added $\mathrm{HCl}$. Therefore, the use of reagents focused on reducing the viscosity of water-in-oil emulsions is designed to provide their improved decomposition. To this end, the next stage of research included experiments to develop a reagent that reduces the viscosity of water-in-oil emulsions stabilized with hydrochloric acid.

\subsection{Development of Viscosity Reducing Agent for Water-in-Oil Emulsions}

Development of a reagent involving over 30 organic compounds: surfactants, alkaline agents, solvents, etc.

The research method was as follows: water solution of hydrochloric acid was prepared using model water, and oil was added to it; the resulting water-in-oil emulsion was mechanically mixed at $1000 \mathrm{rpm}$ for 10 minutes, after which the water-in-oil emulsion was cured for one hour (aging of water-in-oil emulsion). After aging, a commercial demulsifier (currently used in the oilfield) was added to the emulsion at a dosage of $171 \mathrm{~g} / \mathrm{t}$ (process dosage), after which the mixture was stirred at $1000 \mathrm{rpm}$ for 10 minutes. Then, a viscosityreducing agent was added to the system, the emulsion was manually mixed and then cured for 30 minutes. Then, the rheological parameters were determined. The change in viscosity after adding the reagent was monitored.

Of the entire range of tested organic compounds, the components giving a maximum reduction of viscosity at minimal dosages were chosen. The chosen reagents (surfactants, alkaline agents, solvents) were studied in various combinations to determine the synergistic effect in reducing the viscosity of water-in-oil emulsions. Over 12 systems were studied, and below are shown the results of the most efficient combinations of three components: non-ionic surfactant (hydroxyethyl alkylphenol), alkaline organic agent, and solvent (methanol). Table 2 provides an example of the results of the selection of the optimum mass ratio of these components. 
Table 2. Changing of the viscosity of water-in-oil mixtures containing $171 \mathrm{~g} / \mathrm{t}$ of industrial demulsifier and $500 \mathrm{ppm} \mathrm{HCl}$ in the presence of reagents with varying ratios of components.

\begin{tabular}{|c|c|c|c|c|c|c|c|c|c|c|}
\hline $\begin{array}{c}\text { Reag } \\
\text { ent, } \\
\% \\
\text { w/w }\end{array}$ & \multicolumn{2}{|c|}{0.08} & & & \multicolumn{2}{|c|}{0.103} & \multicolumn{2}{|c|}{0.095} & \multicolumn{2}{|c|}{0.093} \\
\hline \multicolumn{11}{|c|}{ Reagent composition, $\% \mathrm{w} / \mathrm{w}$} \\
\hline $\begin{array}{l}\text { Non- } \\
\text { ionic } \\
\text { surfac } \\
\text { tant }\end{array}$ & \multicolumn{2}{|c|}{45} & \multicolumn{2}{|c|}{63} & \multicolumn{2}{|c|}{27} & \multicolumn{2}{|c|}{75} & \multicolumn{2}{|c|}{75} \\
\hline $\begin{array}{c}\text { Alkal } \\
\text { ine } \\
\text { agent }\end{array}$ & \multicolumn{2}{|c|}{45} & \multicolumn{2}{|c|}{27} & \multicolumn{2}{|c|}{63} & \multicolumn{2}{|c|}{0} & \multicolumn{2}{|c|}{15} \\
\hline $\begin{array}{c}\text { Solve } \\
\text { nt }\end{array}$ & \multicolumn{2}{|c|}{10} & \multicolumn{2}{|c|}{10} & \multicolumn{2}{|c|}{10} & \multicolumn{2}{|c|}{25} & \multicolumn{2}{|c|}{10} \\
\hline $\begin{array}{c}\text { Shear } \\
\text { rate, } \\
\text { s }\end{array}$ & $\begin{array}{l}\text { Visco } \\
\text { sity, } \\
\text { mPax } \\
\text { s }\end{array}$ & $\begin{array}{l}\text { Ratio } \\
\text { of } \\
\text { viscosi } \\
\text { ties }\end{array}$ & $\begin{array}{l}\text { Visco } \\
\text { sity, } \\
\text { mPax } \\
\text { s }\end{array}$ & $\begin{array}{l}\text { Ratio } \\
\text { of } \\
\text { viscosi } \\
\text { ties }\end{array}$ & $\begin{array}{l}\text { Visco } \\
\text { sity, } \\
\text { mPax } \\
\text { s }\end{array}$ & $\begin{array}{l}\text { Ratio } \\
\text { of } \\
\text { viscosi } \\
\text { ties }\end{array}$ & $\begin{array}{l}\text { Visco } \\
\text { sity, } \\
\text { mPax } \\
\text { s }\end{array}$ & $\begin{array}{l}\text { Ratio } \\
\text { of } \\
\text { viscosi } \\
\text { ties }\end{array}$ & $\begin{array}{l}\text { Visco } \\
\text { sity, } \\
\text { mPax } \\
\text { s }\end{array}$ & $\begin{array}{l}\text { Ratio } \\
\text { of } \\
\text { viscopi } \\
\text { ties }\end{array}$ \\
\hline 1 & 4617 & 4.8 & 3210 & 6.8 & 3070 & 7.2 & 3769 & 5.0 & 2357 & 8.04 \\
\hline 5 & 1171 & 5.2 & 987 & 6.2 & 1281 & 4.8 & 1160 & 5.1 & 995 & 5.9 \\
\hline 10 & 705 & 4.2 & 580 & 5.1 & 803 & 3.7 & 684 & 4.5 & 637 & 4.9 \\
\hline 30 & 394 & 3.6 & 318 & 4.4 & 433 & 3.3 & 350 & 4.5 & 295 & 5.3 \\
\hline 50 & 312 & 3.7 & 260 & 4.4 & 334 & 3.5 & 277 & 4.5 & 124 & 10.1 \\
\hline 70 & 296 & 3.6 & 254 & 4.2 & 306 & 3.5 & 260 & 4.38 & 57 & 20.0 \\
\hline 100 & 317 & 3.1 & 278 & 3.6 & 279 & 3.6 & 288 & 3.72 & 49 & 21.9 \\
\hline
\end{tabular}

*Ratio of the viscosity of the original emulsion with $550 \mathrm{ppm} \mathrm{HCl}$ and $171 \mathrm{~g} / \mathrm{t}$ of industrial demulsifier to a dynamic viscosity of the water-in-oil emulsion with $500 \mathrm{ppm} \mathrm{HCl}, 171 \mathrm{~g} / \mathrm{t}$ of industrial demulsifier, and $0.08-0.103 \% \mathrm{w} / \mathrm{w}$ of viscosity-reducing agent

It can be seen from Table 2 that an increase in the efficiency of the reagent is observed when an alkaline agent at $15 \% \mathrm{w} / \mathrm{w}$, an increase or decrease in the concentration of this component in the formulation of the viscosity-reducing agent I leads to a decrease in efficiency. Therefore, the optimal composition of the reagent is $75 \% \mathrm{w} / \mathrm{w}$ of nonionic surfactant, $15 \% \mathrm{w} / \mathrm{w}$ of alkaline agent, and $10 \% \mathrm{w} / \mathrm{w}$ of solvent. It should be noted that the performance of the developed reagent improves as the shear rate increases.

In the next stage, the characteristics of the developed preparation was tested for different dosages in the selected optimal component formulation. The results of the study are shown in Table 3. The folding change of viscosity was calculated as the ratio of the viscosity of the original water-in-oil emulsion (containing also $500 \mathrm{ppm} \mathrm{HCl}$ and $171 \mathrm{~g} / \mathrm{t}$ de-emulsifier) to the viscosity of water-in-oil emulsion with the added viscosity reducer (containing also $500 \mathrm{ppm} \mathrm{HCl}$ and $171 \mathrm{~g} / \mathrm{t}$ de-emulsifier).

Table 3. Dependence of the folding change of viscosity from the concentration of the reagent and shear rate $\left(\right.$ at $\left.20^{\circ} \mathrm{C}\right)$.

\begin{tabular}{cccccccc}
\hline \multirow{2}{*}{ Reagent, \% } & \multicolumn{7}{c}{ Shear rate, $\mathrm{s}^{-1}$} \\
\cline { 2 - 8 } & 1 & 5 & 10 & 30 & 50 & 70 & 100 \\
\hline 0.048 & 3.2 & 5.1 & 4.8 & 4.8 & 4.6 & 4.4 & 3.8 \\
0.093 & 8.0 & 5.9 & 4.9 & 5.3 & 10.1 & 20.0 & 21.9 \\
0.239 & 4.1 & 7.4 & 6.9 & 6.4 & 6.0 & 6.4 & 5.2 \\
0.475 & 15.4 & 9.8 & 9.0 & 14.1 & 24.3 & 31.8 & 32.6 \\
\hline
\end{tabular}

The results showed that at a reagent concentration of $0.048 \% \mathrm{w} / \mathrm{w}$, the emulsion 
viscosity was reduced 3.2-4.8 times depending on the shear rate; at a concentration of $0.09 \% \mathrm{w} / \mathrm{w}-5.3-21.9$ times, at a concentration of $0.24 \% \mathrm{w} / \mathrm{w}-4.1-7.4$ times, and at $0.48 \%$ w/w - 9.8-32.6 times.

Thus, the developed reagent can be used to reduce the viscosity of highly stable waterin-oil emulsions formed in the presence of $\mathrm{HCl}$, and its combination with a commercial demulsifier can intensify their decomposition. The technology of using the reagent may consist of the introducing a viscosity-reducing agent at the oil preparation facilities, and its addition will be necessary only in case of formation of the decomposition-stable emulsions when performing ance WITs with the use of hydrochloric acid.

Effective reduction of viscosity of water-in-oil emulsions is important not only for oil treatment facilities, but also at various stages of oil production. For example, adding the reagent in the upper of the well, where stable high-viscosity emulsions are known to form, or capillary injection of the reagent into the inflow of borehole pumps or its introduction by a dosing device on the bottom-hole.

Evaluation of the efficiency of the designed reagent for the above-mentioned technologies included a study of the performance of reagents of different concentrations to reduce the viscosity of the water-in-oil emulsion without adding demulsifier. The results are shown below in Table 4 . The fold change of viscosity was calculated as the ratio of the viscosity of the original water-in-oil emulsion (also containing $500 \mathrm{ppm} \mathrm{HCl}$, no demulsifier added) to the viscosity of the water-in-oil emulsion with added viscosity reduction reagent (also containing $500 \mathrm{ppm} \mathrm{HCl,} \mathrm{no} \mathrm{demulsifier} \mathrm{added).}$

Table 4. Dependence of the fold change of viscosity from the concentration of the reagent and shear rate $\left(\right.$ at $\left.20^{\circ} \mathrm{C}\right)$.

\begin{tabular}{cccccccc}
\hline \multirow{2}{*}{ Reagent, \% } & \multicolumn{7}{c}{ Shear rate, $\mathrm{s}^{-1}$} \\
\cline { 2 - 8 } & 1 & 5 & 10 & 30 & 50 & 70 & 100 \\
\hline 1.01 & 66.0 & 35.4 & 29.8 & 25.5 & 44.0 & 55.3 & 43.8 \\
0.47 & 21.1 & 19.5 & 16.6 & 13.9 & 15.7 & 11.2 & 10.0 \\
0.12 & 10.9 & 13.6 & 11.4 & 9.0 & 8.8 & 7.9 & 6.3 \\
\hline
\end{tabular}

The results showed that at a concentration of $0.12 \% \mathrm{w} / \mathrm{w}$ reagent it was possible to reduce the viscosity of the emulsion 6.3-13.6 times depending on the shear rate, at a concentration of $0.47 \% \mathrm{w} / \mathrm{w}, 10.0-21.1$ times, at a concentration of $1.0 \% \mathrm{w} / \mathrm{w}, 25.5-66.0$ times (results obtained at $20^{\circ} \mathrm{C}$ ).

Thus, the possibility of effective use of the reagent to reduce the viscosity of an waterin-oil emulsion formed in the presence of $\mathrm{HCl}$, and, possibly, with no de-emulsifier added, was demonstrated, which shows the many ways of using this reagent in industrial conditions.

\section{Conclusions}

1. Well intervention techniques used in the major oilfields of the Samara Region were analyzed. The analysis showed that the most common method (over 78\% rel.) is the bottomhole treatment of which about $74 \%$ of cases use hydrochloric acid. It was found that there is an interrelation between WITs using acid and increased water cut of well fluid at the oil preparation facilities which demands adjustment of dosage of demulsifiers and/or changes in the operation of process equipment.

2. Effects of $\mathrm{HCl}$ on surface properties of water-in-oil emulsions were identified. It was experimentally proved that the increased content of demulsifier and hydrochloric acid reduces the interphasial tension, but at concentrations of $\mathrm{HCl} 1300-1400 \mathrm{ppm}$, there occurs 
a further growth of the IPT. The observed patterns of increasing concentrations of hydrochloric acid can be associated with the process of protonation of tars and asphaltenes in the oil and the formation of sediment which, in its turn, leads to the formation of additive surface in the interphase, increasing the IPT value and requires increasing the doses of demulsifier.

3. Changes in rheological properties of water-in-oil emulsion with added hydrochloric acid were evaluated. Experiments showed that the viscosity of emulsion grows exponentially in the presence of hydrochloric acid even at low content (500 ppm). Thus, with the shear rate of $5 \mathrm{~s}^{-1,}$ the viscosity of water-in-oil emulsion with hydrochloric acid is more than 9 times higher than the dynamic viscosity of the emulsion free from acid. The higher the shear rates, the lower the ratio of viscosities while remaining relatively high (dynamic viscosity at $100 \mathrm{~s}^{-1}$ of the water-in-oil emulsion with acid is 2.5 higher than the viscosity of the emulsion without acid). A strong increase in viscosity increases the stability of the water-in-oil emulsion, which significantly impacts its effective decomposition.

4. Studies were performed to evaluate the possibilities of decomposition of HClstabilized water-in-oil emulsions with the use of commercial demulsifiers. The results of experiments showed that none of the demulsifiers used achieved complete separation of the emulsion water, the best specimen having performed at $24 \%$ dewatering (dosage $500 \mathrm{~g} / \mathrm{t}$, settling time 2 hours). Increased duration of water-in-oil emulsion settlement had no significant impact on the efficiency of dewatering. An increase of temperature to $60^{\circ} \mathrm{C}$ improves dewatering performance; however, its efficiency remains rather low at $38 \%$. Thus, the efficiency of decomposition of water-in-oil emulsions with added hydrochloric acid by standard demulsifiers remains low. One of the existing ways of improving the process of decomposition of such emulsions is the use of viscosity-reducing agents that reduce the viscosity of water-in-oil emulsions and enhance the performance of demulsifiers.

5. A viscosity-reducing reagent was developed on the basis of a non-ionic surfactant, alkaline agent, and solvent. Its efficiency in reducing the viscosity was evaluated for $\mathrm{HCl}$ stabilized water-in-oil emulsions in the presence of commercial demulsifiers. It has been found that the proposed formulation of the components in the reagents leads to a decrease in the water-in-oil emulsion viscosity at a concentration of $0.05 \% \mathrm{w} / \mathrm{w}$ in 4.8 times, at a concentration of $0.1 \% \mathrm{w} / \mathrm{w}$ in 5.3 times, at a concentration of $0.24 \% \mathrm{w} / \mathrm{w}$ in 6.4 times, and at a concentration of $0.48 \% \mathrm{w} / \mathrm{w}$ in 14 times. Thus, the developed reagent can be used at the oil treatment facilities to reduce the viscosity of water-in-oil emulsions in combination with commercial demulsifiers to enhance the process of water-in-oil emulsion decomposition.

6. Additional experiments showed that the developed reagent provides reduction of water-oil emulsion viscosity without adding demulsifier. The experiment results showed that at a concentration of the reagent $0.12 \% \mathrm{w} / \mathrm{w}$ the emulsion viscosity was reduced 9.0 times, at a concentration of $0.47 \% \mathrm{w} / \mathrm{w} 14$ times, at a concentration of $1.0 \% \mathrm{w} / \mathrm{w} 25$ times (data provided for a shear rate of $30 \mathrm{~s}^{-1}$ and temperature of $200^{\circ} \mathrm{C}$ ). Thus, the developed reagent can be used at oil treatment facilities to eliminate the formation of highly-viscous water-in-oil emulsions including those in the presence of hydrochloric acid, to improve the performance of submersible pumps and wellbore fluid collecting systems.

\section{References}

1. F.R. Gubaidullin, O.S. Tatyanina, T.F. Kosmacheva, R.Z. Sakhabutdinov, I.H. Ismagilov, Influence of chemical reagents used in the oil production industry on the stability of water-in-oil emulsions. Neftyanoe Khozyaistvo: 8, 68-70. (2003) 
2. R.Z. Sakhabutdinov, F.R. Gubaidullin, I.H. Ismagilov, T.F. Kosmacheva, Specifics of formation and decomposition of water-oil emulsions on the later stages of development of oil fields (Moscow: OJSC "VNIIOENG", 2005).

3. I.F. Glumov, V.V. Slesareva, N.M. Petrova, Influence of hydrochloric acid on the stability of water-in-oil emulsions, Collected Works of TatNIPIneft: Development and operation of oil fields of Tatarstan: 114-117 (2000).

4. Y.M. Ganeeva, T.N. Yusupova, E.E. Barskaya, A.Kh. Valiullova, E.S. Okhotnikova, V.I. Morozov, L.F. Davletshina, The composition of acid/oil interface in acid oil emulsions. Petroleum Science 17(5): 1345-1355 (2020).

5. El-Sayed Abdel-Raouf, Crude oil emulsions - composition stability and characterization. (Manar, 2012).

6. AlMubarak, AlKhaldi, Investigation of Acid-Induced Emulsion and Asphaltene Precipitation in Low Permeability Carbonate Reservoirs. (M.,2015)

7. C.N. Fredd, H.S. Fogler, Alternative stimulation fluids and their impact on carbonate acidizing. SPE J., 13: 34-41 (1998).

8. E.W. Moore, C.W. Crowe, A.R. Hendrickson, Formation, Effect, and Prevention of Asphaltene Sludges During Stimulation Treatments (Society of Petroleum Engineers, 1965).

9. J.A. Rocha, E.N. Baydak, H.W. Yarranton, What fraction of the asphaltenes stabilizes water-in-bitumen emulsions? Energy Fuels, 32: 1440-50. (2018).

10. M.A. Khadim, M.A. Sarbar, Role of asphaltene and resin in oil field emulsions. $J$ Pet Sci Eng, 23: 213-216. (1999).

11. F.A. Rojas-Ruiz, J.A. Orrego-Ruiz, Finding a relationship between the composition and the emulsifying character of asphaltenes through FTICR-MS. $C T \& F, 8: 45-52$ (2018).

12. M.E. Abdel-Raouf, Factors affecting the stability of crude oil emulsions. Abdel-Raouf ME, editor. Crude oil emulsions - composition stability and characterization. InTech: Groatia, 183-201. (2012).

13. P.M. Spiecker, K.L. Gawrys, C.B. Trail, P.K. Kilpatrick, Effects of petroleum resins on asphaltene aggregation and water-in-oil emulsion formation. Colloids Surf A., 220: 9-27 (2003).

14. M. Sedghi, L. Goual, Role of resins on asphaltene stability. Energy Fuels, 24(4): 2275-2280 (2009).

15. J.D. McLean, P.K. Kilpatrick, Effects of asphaltene aggregation in model heptanetoluene mixtures on stability of water-in-oil emulsions. J Colloid Interface Sci; 196(1): 23-34. (1997).

16. M. Rietjens, M.Nieuwpoort, An analysis of crude oil-acid reaction products by sizeexclusion chromatography. Fuel, 80: 33-40 (2001).

17. R.B. De Boer, K. Leerlooyer, M.R.P. Eigner, A.R.D. van Bergen, Screening of Crude Oils for Asphalt Precipitation: Theory, Practice, and the Selection of Inhibitors. (Society of Petroleum Engineer, 1995).

18. Anthony Hutin, Jean-François Argillier, Dominique Langevin. Influence of pH on Oil-Water Interfacial Tension and Mass Transfer for Asphaltenes Model Oils. Comparison with Crude Oil Behavior. (Oil \& Gas Science and Technology, Revue d'IFP Energies nouvelles, Institut Français du Pétrole, 2016). 
19. I.N. Karpenko, V.V. Konovalov, Study of the efficiency of performance of deemulsifier in the presence of hydrochloric acid, Problems of gathering, preparation, and transportation of oil and oil products, 2, 47-58 (2019).

20. L.F. Davletshina, L.I. Tolstykh, P.S. Mikhailova, On the necessity of studying the specifics of behavior of hydrocarbons to improve efficiency of acid treatment of wells. Terrotoriya Neftegaz: 4, 90-96 (2016).

21. M. Rietjens, M. Mieuwpoort, Acid-sludge: How small particles can make a big impact. The Hague, SPE European Formation Damage Conference (1999).

22. V.P. Tronov, Oil preparation in the oilfield. (Kazan: Fen., 2000).

23. V.P. Tronov, Use of chemicals in the technological processes of oilfield development, production of oil, and their interrelation: 14-18 (2002). 